\title{
SIMPLE FORMULAE FOR DAMAGE ESTIMATION OF COMPOSITE STEEL/CONCRETE MOMENT RESISTING FRAMES
}

\author{
George S. Kamaris ${ }^{1}$, Konstantinos A. Skalomenos ${ }^{2}$, George D. Hatzigeorgiou ${ }^{3}$, and \\ Dimitri E. Beskos ${ }^{2,4}$ \\ ${ }^{1}$ School of Engineering, University of Warwick \\ Coventry CV4 7AL, United Kingdom \\ G.Kamaris@warwick.ac.uk \\ ${ }^{2}$ Department of Civil Engineering, University of Patras \\ Patras GR-26500, Greece \\ \{skalomenos,d.e.beskos\}@ upatras.gr \\ ${ }^{3}$ School of Science and Technology, Hellenic Open University \\ Patras GR-26335, Greece \\ hatzigeorgiou@eap.gr \\ ${ }^{4}$ Office of Theoretical and Applied Mechanics, Academy of Athens \\ Athens GR-11527, Greece \\ d.e.beskos@upatras.gr
}

Keywords: Steel/concrete moment resisting frames, Damage indices, Far-fault ground motions.

\begin{abstract}
Simple empirical expressions to estimate maximum seismic damage on the basis of three well known damage indices for planar regular steel/concrete composite moment resisting frames are presented. They are based on the results of extensive parametric studies concerning the inelastic response of a large number of frames to a large number of ordinary farfield type ground motions. Thousands of nonlinear dynamic analyses are performed by scaling the seismic records to different intensities in order to drive the structures to different levels of inelastic deformation. The statistical analysis of the created response databank indicates that the number of stories, beam strength ratio, material strength and the ground motion characteristics affect structural damage. Nonlinear regression analysis is employed in order to derive simple formulae, which offer a direct estimation of the damage indices used in this study. More specifically, given the characteristics of the structure and the ground motion, one can calculate the maximum damage observed in column bases and beams. Finally, one example serves to illustrate the use of the proposed expressions and demonstrates their efficiency and accuracy.
\end{abstract}




\section{INTRODUCTION}

Damage in a structure under loading can be defined as the degradation or deterioration of its integrity resulting in reduction of its load capacity. In earthquake-resistant design of structures, some degree of damage in the structural members is generally accepted. This is done because the cost of a structure designed to remain elastic during a severe earthquake would be very large. Thus, existing seismic codes, e.g., EC8 [1], in an implicit way and more recent performance-based seismic design methods $[2,3,4]$ in an explicit and more systematic way employ the concept of damage to establish structural performance levels corresponding to increasing levels of earthquake actions. These performance levels mainly describe the damage of a structure through damage indices, such as the interstory drift ratio, or the member plastic rotations.

Several methods to determine damage indices as functions of certain response parameters have been presented in the literature. In general, these methods can be noncumulative or cumulative in nature. The most commonly used parameter of the first class is ductility, which relates damage only to the maximum deformation and is still regarded as a critical design parameter by codes. To account for the effects of cyclic loading, simple rules of stiffness and strength degradation have been included in various noncumulative indices [5,6,7], mainly referred to reinforced concrete members. Cumulative-type indices can be divided in deformation based [8] or hysteresis based [9,10] formulations and methods that consider the effective distribution of inelastic cycles and generalize the linear law of low-cycle fatigue of metals through a hypothesis of linear damage accumulation [11]. Sucuoğlu and Erberik [12] developed low-cycle fatigue damage models for deteriorating systems on the basis of test data and analysis and Kamaris et al. [13] proposed a new damage model exhibiting strength and stiffness degradation which takes into account the phenomenon of low-cycle fatigue and the interaction between axial force and bending moment at a section of a beam-column steel member. Combinations of deformation and energy dissipation have been also proposed to establish damage indices [14]. In these methods damage is expressed as a linear combination of the damage caused by excessive deformation and that due to repeated cyclic loading effects [14]. An extensive review of damage indices used in the literature can be found in Powell and Allahabadi [15]. Finally, the concept of continuum damage mechanics [16] in conjunction with the finite element method of concentrated inelasticity has been employed in the analysis of steel and reinforced concrete structures $[17,18]$ for the determination of their damage.

The main objective of this paper is to study the seismic inelastic behavior of plane steel/concrete composite moment resisting frames (MRFs) and quantify their damage through simple expressions that relate the most commonly used damage indices of the literature with the characteristics of the frames and the ground motions. Similar expressions have been proposed by the authors for steel MRFs [19], but research on steel/concrete composite MRFs is still missing. For that reason, a large number of steel/concrete composite MRFs consisting of I steel beams and concrete filled steel tube (CFT) columns are subjected to an ensemble of 100 ordinary (i.e. without near-fault effects) ground motions scaled to different intensities. A response databank is created and a regression analysis is performed in order to derive simple formulae that can be used for the prediction of damage. Finally, one example is utilized to illustrate the use of the proposed formulae and demonstrate their efficiency and accuracy.

\section{DAMAGE INDICES USED IN THIS STUDY}

The proposed damage expressions are associated with three damage indices existing in the literature. These are the damage indices of Park and Ang [14], Roufaiel Meyer [6] and Banon and Veneziano [5]. These indices have been selected here because i) are the most widely used 
in applications and ii) can be easily employed with the aid of the Ruaumoko 2D program [20]. In the following, a brief description of all these three damage indices will be given for reasons of completeness.

The damage index $D_{P A}$ of Park and Ang [14] is expressed as a linear combination of the damage caused by excessive deformation and that contributed by repeated cyclic loading effects, as shown in the following equation:

$$
D_{P A}=\frac{\delta_{m}}{\delta_{u}}+\frac{\beta}{Q_{y} \delta_{u}} \int d E
$$

In the above, the first part of the index is expressed as the ratio of the maximum experienced deformation $\delta_{m}$ to the ultimate deformation $\delta_{u}$ under monotonic loading. The second part is defined as the ratio of the dissipated energy $\int d E$ to the term $\left(Q_{y} \delta_{u}\right) / \beta$, where $Q_{y}$ is the yield strength and the coefficient $\beta$ is a non-negative parameter determined from experimental calibration. In this paper $\beta$ is taken equal to 0.025 , which is a typical value for steel structures [21].

Roufaiel and Meyer [6] proposed that the ratio between the secant stiffness at the onset of failure $M_{m} / \varphi_{m}$ and the minimum secant stiffness reached so far $M_{x} / \varphi_{x}$, can be used as a good indicator of damage. Based on that, they defined the modified flexural damage ratio (MFDR) or $D_{R M}$ as

$$
\begin{gathered}
D_{R M}=M F D R=\max \left[M F D R^{+}, M F D R^{-}\right] \\
M F D R^{+}=\frac{\phi_{x}^{+}}{M_{x}^{+}}-\frac{\phi_{y}^{+}}{M_{y}^{+}} / \frac{\phi_{m}^{+}}{M_{m}^{+}}-\frac{\phi_{y}^{+}}{M_{y}^{+}}, \quad M F D R^{-}=\frac{\phi_{x}^{-}}{M_{x}^{-}}-\frac{\phi_{y}^{-}}{M_{y}^{-}} / \frac{\phi_{m}^{-}}{M_{m}^{-}}-\frac{\phi_{y}^{-}}{M_{y}^{-}}
\end{gathered}
$$

where $\varphi$ is the beam curvature due to a bending moment $M$, the term $M_{y} / \varphi_{y}$ is the initial elastic stiffness and subscripts + and - denote the loading direction.

The Banon and Veneziano [5] analysis is set in a probabilistic context and their model has been calibrated on the basis of 29 different tests on reinforced concrete elements and structures, selected from among the most representative ones in the technical literature. In particular, the damage parameters $d_{1}$ and $d_{2}$ are defined, respectively, as the ratio of stiffness at yielding point to secant stiffness at failure, and the plastic dissipated energy $E_{h}$ normalized with respect to the absorbed energy at the elastic limit. If the elastic-plastic model is used, $d_{1}$ is obviously equal to the ratio of the maximum displacement $x_{\max }$ to the displacement at the elastic limit $x_{y}$. Therefore, according to the notation introduced above, parameters $d_{1}$ and $d_{2}$ can be expressed as

$$
d_{1}=x_{\max } / x_{y}, \quad d_{2}=E_{h} /(1 / 2) F_{y} x_{y}
$$

where $F_{y}$ is the yield strength. Furthermore, modified damage parameters $d_{1}^{*}$ and $d_{2}^{*}$ are introduced of the form

$$
\begin{gathered}
d_{1}^{*}=d_{1}-1 \\
d_{2}^{*}=a d_{2}^{b}
\end{gathered}
$$

where $a$ and $b$ are two parameters which characterize the structural problem and are defined experimentally. For flexure, $x$ and $F$ are replaced by $\theta$ and $M$, respectively. Thus, the damage index $D_{B V}$ is defined as 


$$
D_{B V}=\sqrt{\left(d_{1}^{*}\right)^{2}+\left(d_{2}^{*}\right)^{2}}
$$

\section{PLANE REGULAR CFT-MRFS USED IN THIS STUDY}

\subsection{Design and Characteristics}

A family of 48 plane regular (orthogonal without setbacks) along their height CFT-MRFs are designed for the parametric studies of this work aiming to cover a wide range of structural characteristics of this type of composite structures. These frames have storey height and bay width equal to $3 \mathrm{~m}$ and $5 \mathrm{~m}$, respectively and CFT column sections, as shown in Fig. 1. Moreover, the frames have the following structural characteristics: number of stories, $n_{s}$, with values $1,3,6,9,12,15,18$ and 20 , number of bays, $n_{b}=3$, steel yielding stress ratio $e_{s}=235 / f_{s}$ with the yielding stress $f_{s}$ taking the values of 275 and $355 \mathrm{MPa}$, concrete strength ratio $e_{c}=$ $20 / f_{c}$ with the compressive strength $f_{c}$ taking the values $20 \mathrm{MPa}$. Additionally, the beam-tocolumn stiffness ratio, $\rho$ and column to beam strength ratio, $\alpha$, taking various values within practical limits are also considered. The beam-to-column stiffness ratio $\rho$ of a frame is based on the beam and column properties in the storey closest to the mid-height of the frame and calculated by

$$
\rho=\frac{\sum(I / l)_{b}}{\sum(I / l)_{c}}
$$

where $I$ and $l$ are the second moment of inertia and length of the steel member (column $c$ or beam $b$ ), respectively. The concrete core is considered as cracked and the effective second moment of inertia for the composite section is defined according to EC4 [22]. The parameter $\rho$ definitely controls the behavior of the frame in the elastic range of the response [23]. As $\rho$ increases, the behavior of the frame moves from pure flexural $(\rho=0.0)$ to pure shear $(\rho=\infty)$ behavior. In the inelastic range of the response and especially at higher values of ductility, the influence of $\rho$ is lost since the structure behaves in a mechanism type of mode. Furthermore, Karavasilis et al. [24] have introduced during the investigation of the inelastic seismic response of steel MRFs the beam strength ratio, $\alpha$, which indicates how much stronger are the beams in comparison with the base columns. According to that work [24], the parameter $\alpha$ adopted here is defined as

$$
\alpha=M_{R C, 1, a v} / M_{R B, a v}
$$

where $M_{R C, 1, a v}$ is the average of the plastic moments of resistance of the columns of the first storey and $M_{R B, a v}$ is the average of the plastic moments of resistance of the beams of all the stories of the frame. This parameter quantifies the structural capacity to avoid the formation of a global plastic mechanism which is developed when plastic hinges occur at the base of columns of the first floor and at the ends of beams.

The CFT-MRFs are designed according to the structural Eurocodes 3 [25], 4 [22] and 8 [1] with the aid of the computer programs SAP2000 [26] and MATLAB [27]. The seismic load combination consists of the gravity load $\mathrm{G}+0.3 \mathrm{Q}=27.5 \mathrm{kN} / \mathrm{m}$ on beams plus the earthquake load and the gravity load combination $1.35 \mathrm{G}+1.5 \cdot \mathrm{Q}=42.6 \mathrm{kN} / \mathrm{m}$ with $\mathrm{G}=26 \mathrm{kN} / \mathrm{m}$ and $\mathrm{Q}=$ $5 \mathrm{kN} / \mathrm{m}$ being the dead and live floor loads, respectively. Data for 24 of the 48 frames considered here, are given in [28]. The sectional dimensions of the frames with $355 \mathrm{MPa}$ yield steel stress remain the same in order to clarify the effect of that material parameter.

Every frame is designed for vertical static loads according to Eurocodes 3 [25] and 4 [22] and for seismic loads according to Eurocode 8 [1] using design ground acceleration $\alpha_{g}=$ 
$0.30 \mathrm{~g}$, soil type B (soil factor $S=1.2$ ) and Spectrum Type 1 with behavior factor $q=4$. In addition to the satisfaction of the seismic strength demands in members, other seismic design checks include compliance with stability and drift criteria as well as capacity design considerations (Eurocode 3 [25]; Eurocode 4 [22] and Eurocode 8 [1]. Finally, it should be noted that the assumed building configurations, material properties, member section dimensions, loading conditions, e.t.c., are compatible with the everyday engineer practice.

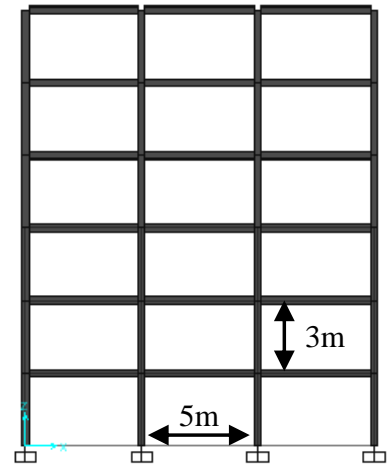

(a)

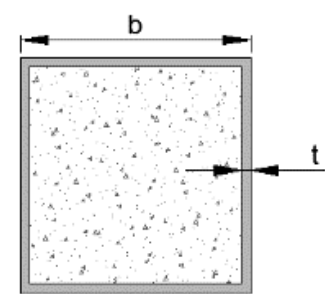

(b)

Figure 1: Typical geometry of frames considered (a) with columns of square concrete filled steel tube (CFT) sections (b).

\subsection{Modelling for nonlinear analysis}

The 48 CFT-MRFs mentioned in the previous section, are subject to a set of 100 accelerograms and their response to those motions is determined through inelastic dynamic time-history analyses using Newmark's constant average acceleration method with the aid of the computer analysis program RUAUMOKO 2D [20]. Diaphragm action is assumed at every floor due to the presence of the slab. The effect of large deformations is taken into account and therefore, the moment amplification in columns caused by the eccentricity of the axial load is considered in the analyses. Rayleigh type damping corresponding to $3 \%$ of the critical damping in the first and second mode is assumed. The deteriorating inelastic behavior of all the frame members is modeled by means of zero-length plastic hinges. The effect of panel zones is taken into account but the connections are assumed to be rigid. All the analytical models of frame components utilized are presented in detail in Skalomenos et al. [28, 30].

\section{GROUND MOTIONS CONSIDERED}

An ensemble of 100 ordinary (far-field type) ground motions recorded at soils with average shear wave velocity $v_{s, 30}$ in the range between 360 and $800 \mathrm{~m} / \mathrm{s}$ (classified according to Eurocode 8 [1] as soil type B) are selected from the PEER [31] database and are employed for the nonlinear time history analyses of this study. Another constraint on the selection of the earthquakes is that their geometric average spectrum be as near as possible to the Eurocode 8 [1] elastic spectrum for ground acceleration $0.30 \mathrm{~g}$ and soil type $\mathrm{B}$, without any scaling. A full list of all these ground motions with their characteristics can be found in Skalomenos [28].

\section{METHODOLOGY FOR COMPUTATION OF DAMAGE EXPRESSIONS}

In the present work, an extensive parametric study was conducted for the 48 CFT-MRFs of described in section 3, which were subjected to the 100 ground motions section 4 for the evaluation of the damage expressions. The frames were analyzed with the program Ruaumoko 
2D [20] using the incremental dynamic analysis method [32]. Thus, approximately 72000 analyses (=48 frames x 100 ground motions x 15 analyses on the average for every frame) were conducted in this work. These 15 on the average analyses for every frame correspond to 15 different PGA values for every ground motion.

The ground motion intensity level was measured here by an intensity measure (IM) equal to the spectral acceleration $S_{a}$, of the motion corresponding to the fundamental period of each frame. The structural response was measured by a damage measure (DM) equal to the maximum damage index among all storeys that was recorded during the time history of the analysis. More specifically, each ground motion was continuously scaled by increasing its $S_{a}$ until the frame to become dynamically unstable and collapse. The results of the analysis were postprocessed in order to create a databank with the response quantities of interest.

The created databank is actually a spreadsheet with rows equal to the number of nonlinear analyses and columns equal to the response quantities of interest in columns and beams of a CFT-MRF along its height. Those response quantities are the maximum values of the following damage indices:1) Park and Ang damage index, $D_{P A}$, 2) Roufaiel and Meyer damage index, $D_{R M}$, 3) Banon and Veneziano damage index, $D_{B V}$. Moreover, the columns of the databank were increased by adding the characteristics of the frames $\left(n_{s}, \rho, \alpha\right)$ and the spectral acceleration $S_{a}$.

\section{DAMAGE FORMULAE FOR COMPOSITE STEEL/CONCRETE MOMENT RESISTING FRAMES}

In this section, simple formulae to estimate seismic damage, through three well known damage indices, of CFT-MRFs are proposed. Thus, with the aid of these simple expressions one can determine the maximum damage of column bases or beams, D, of this type of frames in terms of characteristics of the structure and the ground motions that excite them.

By analyzing the response databank, the proposed relationship was identified and thus the expression

$$
D=b_{1} \cdot n_{s}^{b_{2}} \cdot \alpha^{b_{3}} \cdot\left(\frac{S_{a}}{g}\right)^{b_{4}}\left(\frac{235}{f_{s}}\right)^{b_{5}}
$$

with $b_{1}, b_{2}, b_{3}, b_{4}$ and $b_{5}$ constants to be determined, was selected as a good candidate for approximating the response databank. The aforementioned relation is relatively simple and satisfies the physical constraint $D=0$ for $S_{a}=0$. However, there are values of $S_{a}$ that give 0 values of damage either at columns or beams and for this reason this equation fails to estimate the real value of damage which is 0 . Thus, before using it, one can check the internal forces of the columns or beams by performing a linear analysis and find if their values are in the elastic range. If this is the case the value of damage is equal to zero by default, otherwise the proposed relationship can be used. Use of the Levenberg-Marquardt algorithm [27] for nonlinear regression analysis of the results of parametric studies, led to the following expressions for each one of the three damage indices

a) for column bases:

$$
\begin{aligned}
& D_{P A}^{c}=0.24 \cdot n_{s}^{0.16} \cdot \alpha^{-0.30} \cdot\left(\frac{S_{a}}{g}\right)^{0.39}\left(\frac{235}{f_{s}}\right)^{0.05} \\
& D_{R M}^{c}=0.45 \cdot n_{s}^{0.16} \cdot \alpha^{-0.46} \cdot\left(\frac{S_{a}}{g}\right)^{0.36}\left(\frac{235}{f_{s}}\right)^{0.45}
\end{aligned}
$$




$$
D_{B V}^{c}=0.33 \cdot n_{s}^{0.12} \cdot \alpha^{-0.33} \cdot\left(\frac{S_{a}}{g}\right)^{0.39}\left(\frac{235}{f_{s}}\right)^{0.02}
$$

b) for beams:

$$
\begin{aligned}
& D_{P A}^{b}=0.31 \cdot n_{s}^{0.33} \cdot \alpha^{-0.12} \cdot\left(\frac{S_{a}}{g}\right)^{0.43}\left(\frac{235}{f_{s}}\right)^{-0.08} \\
& D_{R M}^{b}=0.38 \cdot n_{s}^{0.27} \cdot \alpha^{-0.15} \cdot\left(\frac{S_{a}}{g}\right)^{0.37}\left(\frac{235}{f_{s}}\right)^{0.004} \\
& D_{B V}^{b}=0.40 \cdot n_{s}^{0.27} \cdot \alpha^{-0.06} \cdot\left(\frac{S_{a}}{g}\right)^{0.36}\left(\frac{235}{f_{s}}\right)^{-0.10}
\end{aligned}
$$

With $D$ being any damage index of interest, the mean, median and standard deviation of the ratio of the "exact" value of $D$ obtained from inelastic dynamic analyses over the approximate one calculated from Eqs (11) to (16), respectively., i.e., $D_{\text {exact }} / D_{\text {app }}$, are used in order to express the central tendency and the dispersion of the error introduced by the proposed relations. Thus, for the Park and Ang [14] damage index, the ratio $D_{P A, \text { c.exact }} / D_{P A, c, \text { app }}$, for column bases, corresponds to a mean value equal to 1.0, a central value equal to 0.96 and a standard deviation equal to 0.29 . Furthermore, this ratio corresponds to a mean value equal to 1.0and 0.99 , a central value equal to 0.93 and 0.97 and a standard deviation equal to 0.37 and 0.27 for the Roufaiel and Meyer [6] and Banon and Veneziano [5] damage indices, respectively. The above ratio for beams corresponds to a mean value equal to $0.99,1.0$ and 0.99 , a central value equal to $0.96,0.96$ and 0.98 and a standard deviation equal to $0.27,0.28$ and 0.23 for the Park and Ang [14], the Roufaiel and Meyer [6] and Banon and Veneziano [5] damage indices, respectively. Those values show that the proposed formulae are of high accuracy.

\section{EXAMPLE OF APPLICATION}

A three storey-three bay CFT-MRF is examined, with a geometrical configuration similar to the one shown in Fig. 1. The seismic load combination consists of the gravity load $\mathrm{G}+$ $0.3 \mathrm{Q}=27.5 \mathrm{kN} / \mathrm{m}$ on beams plus the earthquake load and the gravity load combination $1.35 \mathrm{G}$ $+1.5 \cdot \mathrm{Q}=42.6 \mathrm{kN} / \mathrm{m}$. The frame has been designed in accordance with the provisions of structural Eurocodes, using design ground acceleration $\alpha_{g}=0.30 \mathrm{~g}$, soil type B (soil factor $S=$ 1.2) and Spectrum Type 1 with behavior factor $q=4$. The yielding stress $f_{s}$ takes the value of $275 \mathrm{MPa}$. The design yielded CFT columns with square steel tubes of width $b=300 \mathrm{~mm}$ and thickness $t=12.5 \mathrm{~mm}$ and IPE 240 beams for all the floors.

The characteristic value $\alpha$ of the frame was computed on the basis of Equation (6) and found to be equal to 2.322. The expected ground motion was defined by the acceleration response spectrum of EC8 [1] with a PGA equal to $0.35 \mathrm{~g}$ and a soil of class B. The fundamental period of vibration, $T$, of the frame is equal to $0.844 \mathrm{~s}$, while its spectral acceleration $S_{a}$ corresponding to this period, derived in the basis of EC8 [1] spectrum, equals $0.64 \mathrm{~g}$.

Eight semi-artificial accelerograms compatible with the EC8 [1] spectrum were generated via a deterministic approach [33] on the basis of eight real seismic records of the database used herein. The response spectra of these motions, in comparison with the EC8 [1] spectrum, are depicted in Fig. 2. Nonlinear time history analyses of the designed frame under these motions were performed. The three damage indices used here and observed in column bases and beams of the frame were computed with the aid of the program Ruaumoko 2D [20]. Then, the 
mean value of the maximum damage values for the eight semi-artificial accelerograms was evaluated for each damage index. Moreover, the approximate values of the damage indices were computed with the aid of Eqs (11) to (16) and recorded together with the exact ones in Tables 1 and 2 for column bases and beams, respectively. The proposed relations predict very well the damage of the beams (error $=5.6-9.5 \%$ ) for all kinds of indices. A similar trend is observed for the columns (error $=4.7-16.0 \%$ ) for all kinds of indices. Thus, the predictions of the proposed formulae are quite close to the "exact" ones and they are as far as the columns, in most of cases, in the safe (conservative) side.

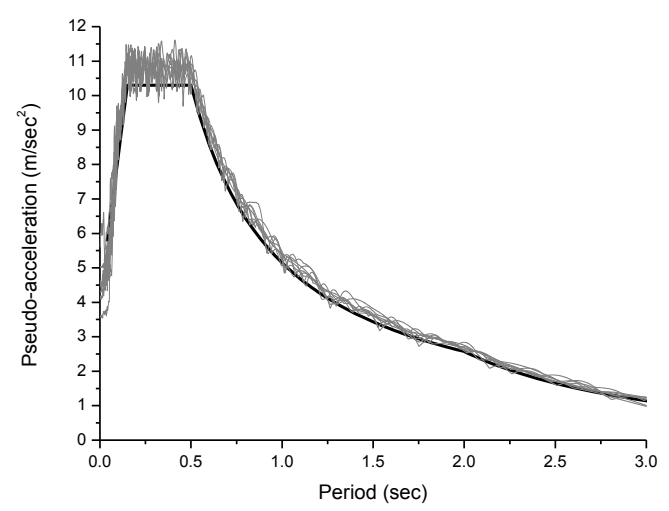

Figure 2: Response spectra of ground motions used in example of sec 7.

\begin{tabular}{cccc}
\hline $\begin{array}{l}\text { Damage } \\
\text { Index }\end{array}$ & $\begin{array}{c}\text { "Exact" } \\
\text { Value }\end{array}$ & $\begin{array}{l}\text { Approximate } \\
\text { Value }\end{array}$ & Error $(\%)$ \\
\hline$D_{P A}$ & 0.157 & 0.187 & 16.0 \\
$D_{R M}$ & 0.273 & 0.287 & 4.7 \\
$D_{B V}$ & 0.203 & 0.240 & 15.6 \\
\hline
\end{tabular}

Table 1: Comparison between "exact" and approximate values of damage indices for columns of the CFT-MRF of the example of sec 7 .

\begin{tabular}{llcc}
\hline $\begin{array}{l}\text { Damage } \\
\text { Index }\end{array}$ & $\begin{array}{c}\text { "Exact" } \\
\text { Value }\end{array}$ & $\begin{array}{l}\text { Approximate } \\
\text { Value }\end{array}$ & Error(\%) \\
\hline$D_{P A}$ & 0.355 & 0.335 & 5.6 \\
$D_{R M}$ & 0.408 & 0.384 & 5.9 \\
$D_{B V}$ & 0.494 & 0.447 & 9.5 \\
\hline
\end{tabular}

Table 2: Comparison between "exact" and approximate values of damage indices for beams of the CFT-MRF of the example of sec 7 .

\section{CONCLUSIONS}

A procedure in terms of simple formulae for estimating the maximum damage in regular multi-storey CFT-MRFs subjected to ordinary (i.e. without near-fault effects) ground motions has been presented. Particularly, simple and easy to use relationships were derived for the computation of three damage indices of the literature, which take into account the influence of basic characteristics of CFT-MRFs and ground motions, such as the number of stories, beam strength ratio, steel yielding stress ratio and the spectral acceleration. It should be noticed 
herein that the proposed relations are valid for frames with characteristics similar to those of the frames used in the parametric studies and for seismic sites where ordinary ground motions are expected. These expressions give a good approximation of damage and provide a rapid damage assessment of existing structures without the use of the more sophisticated and time consuming non-linear dynamic analysis.

\section{REFERENCES}

[1] EC8. Design of structures for earthquake resistance, Part 1: General rules, seismic actions and rules for buildings, European Committee for Standardization (CEN), Brussels, Belgium, 2004.

[2] P. Fajfar and H. Krawinkler, Seismic Design Methodologies for the Next Generation of Codes. Bled, Balkema, Rotterdam, 24-27 June 1997.

[3] FEMA. FEMA-273 Building Seismic Safety Council, NEHRP guidelines for the seismic rehabilitation of buildings, Federal Emergency Management Agency, Washington (DC), 1997.

[4] G.S. Kamaris, G.D. Hatzigeorgiou, D.E. Beskos, Direct damage controlled seismic design of plane steel degrading frames. Bulletin of Earthquake Engineering, in press.

[5] H. Banon, D. Veneziano, Seismic safety of reinforced concrete members and structures. Earthquake Engineering and Structural Dynamics, 10, 179-173, 1982.

[6] M.S. Roufaiel C. Meyer, Analytical modeling of hysteretic behavior of R/C frames. Journal of Structural Engineering, ASCE, 113, 429-444, 1987.

[7] E. Cosenza, G. Manfredi, R. Ramasco, The use of damage functionals in earthquake engineering: A comparison between different methods. Earthquake Engineering and Structural Dynamics, 22, (10), 855-868, 1993.

[8] J.E. Stephens, J.T.P. Yao, Damage assessment using response measurements. Journal of Structural Engineering, ASCE, 113, 787-801, 1987.

[9] S.L. McCabe, W.J. Hall, Assessment of seismic structural damage. Journal of Structural Engineering, ASCE, 115, 2166-2183, 1989.

[10] J.M. Bracci, A.M. Reinhorn, J.B. Mander, Deterministic model for seismic damage evaluation of reinforced concrete structures, Technical Report NCEER 89-0033, State University of New York at Buffalo, 1989.

[11] H. Krawinkler, M. Zohrei, Cumulative damage in steel structures subjected to earthquake ground motions. Computers and Structures, 16, 531-541, 1983.

[12] H. Sucuoğlu, A. Erberik, Energy-based hysteresis and damage models for deteriorating systems. Earthquake Engineering and Structural Dynamics, 33, 69-88, 2004.

[13] G.S. Kamaris, G.D. Hatzigeorgiou, D.E. Beskos, A new damage index for plane steel frames exhibiting strength and stiffness degradation under seismic motion. Engineering Structures, 46, 727-736, 2013.

[14] Y-J. Park, AH-S. Ang, Mechanistic seismic damage model for reinforced concrete. Journal of Structural Engineering, ASCE, 111, 722-739, 1985. 
[15] G.H. Powell, R. Allahabadi, Seismic damage prediction by deterministic methods: concepts and procedures. Earthquake Engineering and Structural Dynamics, 16, 719-734, 1988.

[16] J. Lemaitre, A Course on Damage Mechanics. Springer-Verlag, Berlin, 1992.

[17] G.D. Hatzigeorgiou, D.E. Beskos, Direct damage controlled design of concrete structures. Journal of Structural Engineering, ASCE, 133, 205-215, 2007.

[18] G.S. Kamaris, G.D. Hatzigeorgiou, D.E. Beskos, Direct damage controlled design of plane steel-moment resisting frames using static inelastic analysis. Journal of Mechanics of Materials and Structures, 4, 1375-1393, 2009.

[19] G.S. Kamaris, Y.-M. Vallianatou, DE. Beskos, Seismic damage estimation of in-plane regular steel moment resisting and x-braced frames. Bulletin of Earthquake Engineering, 10, (6), 1745-1766, 2012.

[20] A.J. Carr, RUAUMOKO-2D. Inelastic Time-History Analysis of Two-Dimensional Framed Structures, Department of Civil Engineering. University of Canterbury, New Zealand, 2006.

[21] C.A. Castiglioni, R. Pucinotti, Failure criteria and cumulative damage models for steel components under cyclic loading. Journal of Constructional Steel Research, 65, 751$765,2009$.

[22] EC4: Design of composite steel and concrete structures - Part 1.1: General rules and rules for buildings, European Committee for Standardization (CEN), Brussels, Belgium, 2004.

[23] S. Akkar, U. Yazgan, and P. Gülkan, Drift estimates in frame buildings subjected to near-fault ground motions, Journal of Structural Engineering, 131, 1014-1024, 2005.

[24] T.L. Karavasilis, N. Bazeos, DE. Beskos, Drift and Ductility Estimates in Regular Steel MRF Subjected to Ordinary Ground Motions: A Design-Oriented Approach. Earthquake Spectra, 24, (2), 431-451, 2008.

[25] EC3. Design of steel structures - Part 1.1: General rules and rules for buildings, European Committee for Standardization (CEN), Brussels, Belgium, 2005.

[26] SAP2000. Static and Dynamic Finite Element Analysis of Structures - V16. Computers and Structures Inc., Berkeley, California, 2013.

[27] MATLAB. The language of technical computing, Version 5.0. The Mathworks Inc., Natick, Mass, 2009.

[28] K.A. Skalomenos, Seismic performance of plane moment resisting frames with concrete filled steel tube columns and steel I beams. Ph.D. Dissertation, Department of Civil Engineering, University of Patras, Greece, 2014.

[29] K.A. Skalomenos, G.D. Hatzigeorgiou, D.E. Beskos, Parameter identification of three hysteretic models for the simulation of the response of CFT columns to cyclic loading. Engineering Structures, 61, 44-60, 2014.

[30] K.A. Skalomenos, G.D. Hatzigeorgiou, DE. Beskos, Modelling level selection for seismic analysis of CFT/MRFs by using fragility curves. Earthquake Engineering Structural Dynamics, in press. 
[31] NGA Strong ground motion database. Pacific Earthquake Engineering Research Center, /http://peer.berkeley.edu, 2011.

[32] D. Vamvatsikos, CA. Cornell, Incremental dynamic analysis. Earthquake Engineering Structural Dynamics, 31, (3), 491-514, 2002.

[33] D.L. Karabalis, G.J. Cokkinides, D.C. Rizos, Seismic Record Processing ProgramVer.1.03, Report of the College of Engineering, University of South Carolina, Columbia, 1992. 